\title{
Evaluating estuarine nursery use and life history patterns of Pomatomus saltatrix in eastern Australia
}

\author{
H. T. Schilling ${ }^{1,2, *}$, P. Reis-Santos ${ }^{3,4}$, J. M. Hughes ${ }^{5}$, J. A. Smith ${ }^{1,2}$, J. D. Everett ${ }^{1,2}$, \\ J. Stewart ${ }^{5}$, B. M. Gillanders ${ }^{4}$, I. M. Suthers ${ }^{1,2}$ \\ ${ }^{1}$ Evolution and Ecology Research Centre, University of New South Wales, Sydney, NSW 2052, Australia \\ ${ }^{2}$ Sydney Institute of Marine Science, Building 19, Chowder Bay Road, Mosman, NSW 2088, Australia \\ ${ }^{3}$ MARE - Marine and Environmental Sciences Centre, Faculdade de Ciências, Universidade de Lisboa, \\ 1749-016 Campo Grande, Lisboa, Portugal \\ ${ }^{4}$ Southern Seas Ecology Laboratories, School of Biological Sciences, The University of Adelaide, SA 5005, Australia \\ ${ }^{5}$ New South Wales Department of Primary Industries, Chowder Bay Road, Mosman, NSW 2088, Australia
}

\begin{abstract}
Estuaries provide important nursery habitats for juvenile fish, but many species move between estuarine and coastal habitats throughout their life. We used otolith chemistry to evaluate the use of estuaries and the coastal marine environment by juvenile Pomatomus saltatrix in eastern Australia. Otolith chemical signatures of juveniles from 12 estuaries, spanning $10^{\circ}$ of latitude, were characterised using laser ablation-inductively coupled plasma-mass spectrometry. Based upon multivariate otolith elemental signatures, fish collected from most estuaries could not be successfully discriminated from one another. This was attributed to the varying influence of marine water on otolith elemental composition in fish from all estuaries. Using a reduced number of estuarine groups, the multivariate juvenile otolith elemental signatures and univariate $\mathrm{Sr}: \mathrm{Ca}$ ratio suggest that between 24 and $52 \%$ of adult $P$. saltatrix had a juvenile period influenced by the marine environment. Elemental profiles across adult (age-1) otoliths highlighted a variety of life history patterns, not all consistent with a juvenile estuarine phase. Furthermore, the presence of age-0 juveniles in coastal waters was confirmed from historical length-frequency data from coastal trawls. Combining multiple lines of evidence suggests considerable plasticity in juvenile life history for $P$. saltatrix in eastern Australia through their utilisation of both estuarine and coastal nurseries. Knowledge of juvenile life history is important for the management of coastal species of commercial and recreational importance such as $P$. saltatrix.
\end{abstract}

KEY WORDS: Otolith chemistry $\cdot$ Elemental profiles $\cdot$ Bluefish $\cdot$ Tailor $\cdot$ Strontium $\cdot$ Barium

\section{INTRODUCTION}

Estuaries function as nursery grounds for juveniles of many coastal fish species, providing refuge, food and habitat (Beck et al. 2001, Able 2005). Many species subsequently emigrate from estuaries to join adult populations in coastal waters, with the duration of the estuarine life history stage ranging from months to years (Gillanders et al. 2003, Fodrie \& Herzka 2008). Assessing connectivity between estuarine and coastal environments is critical for the

${ }^{*}$ Corresponding author: h.schilling@unsw.edu.au

${ }^{\S}$ Advance View was available online April 17, 2018 management of coastal species, but is a complex task, due to the constraints and logistical difficulties of mark-recapture studies using juvenile fish. An alternative approach is to use the elemental composition of fish otoliths or other calcified structures, which allows insights into how species use estuarine and coastal environments throughout their life history (Gillanders et al. 2003, Brown 2006, Izzo et al. 2016).

In recent decades, otolith chemistry has become an increasingly popular tool to investigate multiple aspects of fish life history. As fish otoliths are biolog-

() The authors and UNSW Australia 2018. Open Access under Creative Commons by Attribution Licence. Use, distribution and reproduction are unrestricted. Authors and original publication must be credited. Publisher: Inter-Research · www.int-res.com 
ically inert and grow continuously, trace elements from the surrounding environment are incorporated on the growing surface of the otolith (Campana \& Thorrold 2001). Since water masses are known to vary in their environmental conditions over time and space, fish collected in different environments are expected to have different otolith elemental composition (Campana et al. 2000). These elemental 'signatures' or 'fingerprints' have been used to successfully identify natal origins and nursery estuaries of adult fish (Gillanders \& Kingsford 1996, Gillanders 2002a, Vasconcelos et al. 2011, Reis-Santos et al. 2013), discriminate between populations (Rooker et al. 2001, Tanner et al. 2016) and determine mixed stock composition (Munch \& Clarke 2008, Geffen et al. 2011).

Otoliths are also used as environmental chronometers of temporal variation in elemental concentrations. Through analysis of elemental profiles from the core to the edge of otoliths, a continuous record of how elements change in concentration throughout the life of a fish may be revealed (Campana \& Thorrold 2001). In particular, profiles of strontium and barium have been used successfully in reconstructing environmental and estuary-ocean migration histories for individual fish (Elsdon \& Gillanders 2005a, Fowler et al. 2016), as concentrations of these elements are strongly influenced by salinity (Secor \& Rooker 2000, Walther \& Limburg 2012). If fish movement occurs over a large salinity gradient, it is more likely to be detected, and hence most research has focused on migrations between freshwater and marine environments. However, studies reconstructing habitat use and environmental life histories along narrow salinity gradients are becoming more common (Tanner et al. 2013, Williams et al. 2018).

Tailor or bluefish (Pomatomus saltatrix) is a globally distributed pelagic mesopredator that is fished commercially and recreationally throughout its range. Stark differences in life history patterns exist between populations (Juanes et al. 1996), particularly in growth rates and average maximum size $\left(L_{\infty}\right)$. For example, $L_{\infty}$ in the west Atlantic Ocean is more than double that in the Mediterranean (Ceyhan et al. 2007, Robillard et al. 2009). In general, adult P. saltatrix undertake annual migrations along the coast before spawning at sea, with larvae that are then distributed by ocean currents to downstream areas (Juanes et al. 1996). While larvae recruit to both estuarine and coastal areas in most global populations, in eastern Australia, larvae have only been documented to recruit to estuaries (Miskiewicz et al. 1996), where they remain until they emigrate to coastal marine waters at approximately $27 \mathrm{~cm}$ fork length (FL) (Mor- ton et al. 1993, Zeller et al. 1996), corresponding to approximately 1 yr of age (Dodt et al. 2006, H.T.S. unpubl. data). This contrasts with the life history of other populations, namely the eastern Indian Ocean and western Atlantic Ocean populations, which have both coastal and estuarine recruitment (Lenanton et al. 1996, Able et al. 2003, Callihan et al. 2008). It is likely that juvenile tailor in eastern Australia use both estuarine and coastal habitat, and this discrepancy in juvenile habitat use has previously been identified as warranting further attention (Juanes et al. 1996).

Otolith chemistry is an ideal tool with which to investigate life history plasticity and the use of estuarine and coastal juvenile habitats by $P$. saltatrix. The broad goal of this study was to use otolith chemistry techniques to gain insight into the life history of $P$. saltatrix in eastern Australia, specifically estuarineocean movements, and to compare these to the life history patterns exhibited by populations elsewhere. Specifically, we tested whether: (1) otoliths of juvenile $P$. saltatrix from different estuaries had characteristic elemental signatures; (2) adult $P$. saltatrix could be assigned to juvenile habitats types based on the elemental signatures from the juvenile area of their otoliths; and (3) elemental profiles from the core to the edge of adult $P$. saltatrix support movement between estuarine and oceanic habitats.

\section{MATERIALS AND METHODS}

\section{Fish collection}

Juvenile Pomatomus saltatrix ( $\mathrm{n}=360$, age- 0 ) were collected from 12 estuaries along the east coast of Australia over 2 southern hemisphere summers (2014/15 and 2015/16; Fig. 1; see Table S1 in the Supplement at www.int-res.com/articles/suppl/m598p187_supp. pdf). Fish were collected from 2 haphazardly selected sites at least $1 \mathrm{~km}$ apart within each estuary. As $P$. saltatrix were not found in all estuaries in both years, some estuaries only had fish collected from one summer. Fish were collected with baited handlines and frozen prior to dissection in the laboratory.

Adult $P$. saltatrix ( $\mathrm{n}=121$, age-1) were also collected from both estuarine and coastal habitats along the east coast of Australia during the 2015-2016 summer (to match the 2014-2015 juvenile cohort; Table S1 in the supplement). These fish were collected by commercial fishers or donated by recreational fishers. All fish were frozen prior to dissection. To confirm fish were from the correct cohort, the 


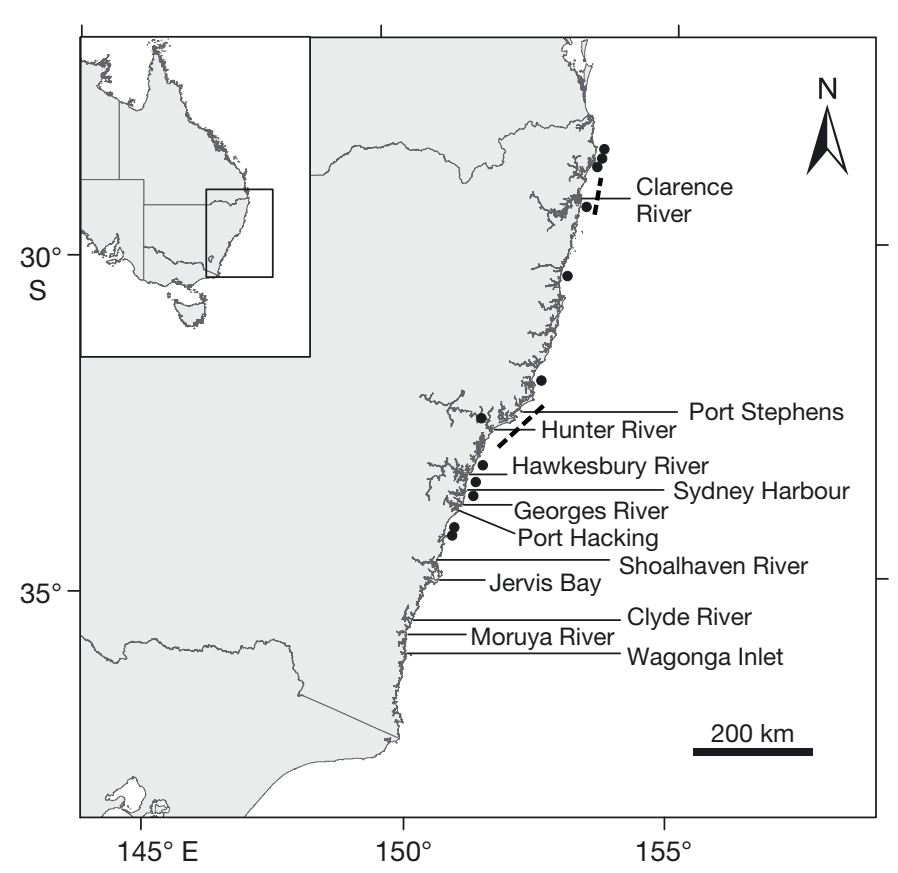

Fig. 1. Locations of the estuaries where juvenile Pomatomus saltatrix were collected. The dashed lines represent the regions where offshore trawl samples were conducted during the 1990s. These trawls were conducted at 2 depths: 5-27 m and 64-77 m (Graham et al. 1993a,b, Graham \& Wood 1997). Each black circle represents the capture location of a 1-yrold $P$. saltatrix used in the elemental profile analysis

ages of all fish were estimated from whole otoliths viewed using a light microscope under water with reflected light. This estimated age was subsequently confirmed after transverse sectioning for otolith chemical analysis (see below) and viewing the section under reflected light (H.T.S. unpubl. data, Robillard et al. 2009). Only fish aged 1 yr were selected for subsequent analysis. The age and size at sexual maturity of $P$. saltatrix in eastern Australia are $1 \mathrm{yr}$ and approximately $27 \mathrm{~cm} \mathrm{FL}$, respectively (Bade 1977, H.T.S. unpubl. data).

\section{Otolith element analysis}

To characterise the elemental signatures of $P$. saltatrix from each estuary, sagittal otoliths were embedded in indium-spiked $\left({ }^{115} \mathrm{In}\right)$ resin $(\sim 40 \mathrm{ppm})$ and sectioned transversely. The sections were then polished using fine lapping paper and fixed to microscope slides with ${ }^{115}$ In-spiked thermoplastic glue ( 200 ppm; Hughes et al. 2016), and subsequently cleaned and sonicated with ultrapure water. Otolith sections were analysed at Adelaide Microscopy (The University of Adelaide) using a New Wave UP-213- $\mathrm{nm}$ laser ablation system connected to an Agilent 7500cs inductively coupled plasma-mass spectrometer (LA-ICP-MS). The laser was run using a spot size of $30 \mu \mathrm{m}$, at a frequency of $5 \mathrm{~Hz}$ and fluence of $7 \mathrm{~J}$ $\mathrm{cm}^{-2}$. A single spot was ablated on the outer edge of each otolith along the proximal surface, beside the sulcal groove. Spots at the outer edge of the juvenile otoliths were used to characterise the elemental fingerprint of each estuary (i.e. representative of collection site) as this is the material most recently incorporated into the otolith (Elsdon et al. 2008). An inner spot was also ablated on otoliths of adult (age 1) fish along the same axis as the outer spot, and corresponded to ablation of material accreted when these fish were juveniles. These inner spots were located ca. $250 \mu \mathrm{m}$ from the core, which was the average distance that the corresponding edge spots in juveniles were from the core. The elemental signature of these inner spots should be indicative of the habitat adult fish used as juveniles. The element concentrations measured (and their associated dwell times) were ${ }^{7} \mathrm{Li}$ $(150 \mathrm{~ms}),{ }^{24} \mathrm{Mg}(100 \mathrm{~ms}),{ }^{43} \mathrm{Ca}(100 \mathrm{~ms}),{ }^{55} \mathrm{Mn}(150 \mathrm{~ms})$, ${ }^{63} \mathrm{Cu}(100 \mathrm{~ms}),{ }^{66} \mathrm{Zn}(100 \mathrm{~ms}),{ }^{88} \mathrm{Sr}(100 \mathrm{~ms}),{ }^{115} \mathrm{In}(10 \mathrm{~ms})$, ${ }^{138} \mathrm{Ba}(100 \mathrm{~ms})$ and ${ }^{208} \mathrm{~Pb}(150 \mathrm{~ms}) .{ }^{43} \mathrm{Ca}$ was used as an internal standard and ${ }^{115}$ In was analysed solely to detect any contamination by resin or thermoplastic glue.

Otolith sections of 12 adult fish were randomly selected for analysis of elemental profiles from the core to the edge. The profiles were run at a scan speed of $3 \mu \mathrm{m} \mathrm{s}^{-1}$ using the same instrument settings described above but only for the elements ${ }^{43} \mathrm{Ca}$, ${ }^{55} \mathrm{Mn},{ }^{88} \mathrm{Sr},{ }^{115} \mathrm{In}$ and ${ }^{138} \mathrm{Ba}$. There is no experimental validation of the relationship between salinity and otolith elemental concentrations for $P$. saltatrix, so it was assumed that the element:Ca ratios on the edges of otoliths represent capture environment, and the average $\mathrm{Sr}: \mathrm{Ca}$ ratios of the edges of otoliths from adults collected from coastal marine waters were used as reference criteria to characterise the estuarine or coastal marine environments (Milton et al. 2008). The resulting average $\mathrm{Sr}$ :Ca ratio from fish captured in coastal marine environments was $2.18 \mathrm{mmol} \mathrm{mol}^{-1}$. We therefore defined $\mathrm{Sr}$ :Ca ratios greater than this value as representing coastal marine environments and any value below this value as representing estuarine or brackish environments. Ba:Ca thresholds were calculated in the same way, but there was no difference between edge otolith $\mathrm{Ba}: \mathrm{Ca}$ of fish from estuarine and coastal collection areas (Welch twosample $t$-test: $t_{28}=1.42, \mathrm{p}=0.176$ ); therefore, $\mathrm{Ba}: \mathrm{Ca}$ was not used to characterise environments fish had spent time in. 
Periodic ablations on certified reference materials (glass standard NIST 612 and carbonate standard MACS-3) were used to calibrate elemental concentrations, correct mass bias and instrument drift, and assess external precision. Prior to data collection and before each ablation, background concentrations of elements within the sample chamber were measured for $40 \mathrm{~s}$. A washout delay of $30 \mathrm{~s}$ was used between each ablation to allow the chamber to purge and prevent samples from becoming cross-contaminated. Raw count data for the spot analyses were processed using the GLITTER software program (Griffin et al. 2008). Profile data reductions were performed manually using spreadsheet software (Microsoft Excel). All elemental data were expressed as ratios to ${ }^{43} \mathrm{Ca}$ (in mmol mol ${ }^{-1}$ ) to account for fluctuations in the ablation yield (Munro et al. 2008). In the few cases where data fell below the limit of detection, the raw data were used because substituting values with an arbitrary number has been shown to bias data owing to non-random patterns in the distribution of small values (Helsel 2006, Schaffler et al. 2014, Lazartigues et al. 2016).

\section{Statistical analysis}

PERMANOVA and canonical analysis of principal coordinates (CAP) were used to analyse the elemental data, using PERMANOVA+ for PRIMER software (Anderson et al. 2008). Prior to analysis, the elemental variables in each dataset were normalised and assumptions were checked using shade plots, which confirmed the equal spread of variance within each dataset (Clarke et al. 2014).

The factors in the PERMANOVA analysis were 'estuary' (fixed), 'year' (fixed) and 'site' (random, nested within estuary), and 'fork length' was included as a covariate because otolith chemistry can vary with ontogeny (Beer et al. 2011). Euclidean distances were used to calculate the resemblance matrix. Type I sum of squares was used in the analysis so that the factor 'estuary' was fitted to the data after the covariate. Permutations were conducted on residuals under a reduced model, rather than on raw data, to avoid inflated Type 1 error rates associated with covariates in multivariate analyses (Anderson et al. 2008). P-values were generated using 9999 permutations. This PERMANOVA analysis was performed on the multivariate (elemental 'signature') data as well as univariate element data.

CAP was used to visualise multivariate differences in otolith elemental signatures between estuaries, and to determine how accurately juvenile individuals could be allocated to their collection estuary. The goal of this was to assign juveniles of known estuaries back to the area of collection; therefore a full baseline of all estuaries in which tailor may be found was unnecessary. Following initial analysis, which found that most estuaries could not be discriminated accurately (see 'Results' for details), 3 groups were formed to improve discrimination accuracy. These groups represent the most marine-dominated estuary in NSW (highest salinity; Jervis Bay; mean $=35.0$, $\min =32.5, \max =36.0, \mathrm{SD}=0.7 ; \mathrm{CSIRO} 1994)$, the estuary with the largest freshwater input in NSW (lowest salinity; Clarence River; mean $=22.7, \mathrm{~min}=$ 5.4, $\max =35.7, \mathrm{SD}=9.2$; NSW Office of Environment and Heritage 2012) and 'Other estuaries', which were a mix of smaller estuaries of variable freshwater input and size $($ mean $=30.8, \min =6.4, \max =35.7$, $\mathrm{SD}=3.7$; NSW Office of Environment and Heritage 2012). These 3 groups were selected as a parsimonious representation of the potential types of estuarine habitat used by juvenile $P$. saltatrix. CAP allows additional samples to be placed onto the canonical axes of an existing CAP model and thereby classifies each of the new unknown origin samples to an existing group. Using this procedure, the elemental signatures from the juvenile section of otoliths of 121 adult fish were added onto the existing CAP model to identify the most likely nursery origins of the adult fish [i.e. whether they had a marine influenced signature (Jervis Bay) or an estuarine influenced signature (Clarence River or 'Other estuaries')]. Fish that had signatures that placed them outside the boundaries of the current CAP analysis were removed ( $\mathrm{n}=3$ ), as this suggests that they came from areas that were not characterised in our analysis.

As an additional concurrent univariate analysis, the Sr:Ca values from the spot analyses of the juvenile section of adult otoliths were arranged to visualise the spectrum of Sr:Ca values observed within juvenile regions, aiming at representing sites used by juveniles relative to the $2.18 \mathrm{mmol} \mathrm{mol}^{-1} \mathrm{Sr}$ :Ca break between coastal marine and estuarine environments.

Otolith elemental profile data from age-1 tailor were smoothed with a 7 -point moving average and plotted relative to distance from the primordium. Fish with similar profiles of both Sr:Ca and Ba:Ca were considered to be representative of different $P$. saltatrix life histories. Despite no difference in Ba:Ca being observed in our saline estuarine and coastal samples described above, high Ba:Ca values were still interpreted as indicative of high freshwater influence. 


\section{Historical offshore length frequency analysis}

To provide additional support for the findings from the otolith chemistry analyses regarding habitat use and life history patterns, a re-analysis of historical trawl data was undertaken. Length-frequency and abundance data for $P$. saltatrix were compiled from a multi-species dataset from 2 sets of research voyages conducted by the RV 'Kapala' between 1990-1992 and 1995-1996. The original aim of the research voyages was to determine the relative abundances and size composition of prawns and associated bycatch species on trawling grounds in the Newcastle and Clarence River regions (Graham et al. 1993a,b, Graham \& Wood 1997). The trawls were conducted in coastal waters of 2 regions, near the Clarence River (northern NSW; 28.5-29.5 ${ }^{\circ}$; Fig. 1) and near Newcastle/Tuncurry (central NSW; 32-33 S; Fig. 1). Within these regions, both inshore (5-27 $\mathrm{m}$ depth) and offshore (64-77 $\mathrm{m}$ depth) trawl transects were conducted. The trawling was conducted with three $22 \mathrm{~m}$ headline Florida Flyer prawn nets towed in a triple-rig arrangement. Fish were measured onboard the RV 'Kapala' for fork length.

\section{RESULTS}

\section{Juvenile elemental signatures by estuary}

Variations in juvenile otolith element:Ca ratios among estuaries were evident (Fig. 2). For instance, higher Ba:Ca and Mn:Ca ratios were found in otoliths from Clarence River than from the other estuaries sampled. Using multivariate PERMANOVA, significant differences were found between estuaries as well as between sites (nested within estuary; Table 1).

Table 1. Summary of PERMANOVA results for the multivariate analysis of edge otolith elemental compositions of juvenile Pomatomus saltatrix collected in different estuaries. There were $>9000$ unique permutations for each term in the model

\begin{tabular}{|lcccc|}
\hline & df & MS & Pseudo- $F$ & p (perm) \\
\hline Fork length & 1 & 106.46 & 8.2391 & 0.0001 \\
Estuary & 11 & 26.595 & 1.6642 & 0.0479 \\
Year & 1 & 18.699 & 2.6345 & 0.1735 \\
Site(Estuary) & 14 & 13.174 & 1.9321 & 0.0012 \\
Estuary $\times$ Year & 3 & 10.657 & 2.3534 & 0.2458 \\
Year $\times$ Site(Estuary) & 2 & 4.159 & 0.60998 & 0.6741 \\
Residuals & 327 & 6.8183 & & \\
Total & 359 & & & \\
\hline
\end{tabular}

Fork length as a covariate was also significant. Pairwise tests of estuaries revealed that only some estuaries were significantly different to each other (Table $\mathrm{S} 2$ in the Supplement). The significant effects of estuary and site show that variation in otolith chemistry of Pomatomus saltatrix could be used for discrimination of groups in some situations. Overall, univariate PERMANOVAs found a significant effect of estuary for $\mathrm{Mg}$, significant site (nested within estuary) effects for $\mathrm{Mn}, \mathrm{Sr}$ and $\mathrm{Ba}$, and a significant estuary $\times$ year interaction for Sr (see Table S3 in the Supplement for full univariate PERMANOVA results).

This study was unable to successfully classify fish to estuaries of capture based on their multivariate otolith elemental signatures (with only $31 \%$ of individuals correctly classified), but classification success varied greatly among estuaries (Table 2). Classification accuracies for Jervis Bay, Wagonga Inlet and Clarence River were the highest (68.4, 52.0 and $50.0 \%$ accuracy respectively), and as Jervis Bay and Clarence River correspond to estuaries with different freshwater flow (highest and lowest salinity), further classification analysis was undertaken (see 'Materials and methods' for full justification). Classification analysis using only 3 groups (Jervis Bay, Clarence River and 'Other estuaries') had an improved overall classification rate of $86 \%$. Individual classification success for each group was $73 \%$ for Jervis Bay, 62\% for Clarence River and $89 \%$ for 'Other estuaries'. While the overall classification accuracy for both the CAP analysis with 12 groups and the CAP analysis with 3 groups was approximately 3 times better than random, the higher allocation

Table 2. Summary of total correct cross-validated individuals of juvenile Pomatomus saltatrix classified back to the estuary in which they were caught, based upon otolith elemental chemistry and canonical analysis of principal coordinates (CAP). The \% allocation to each estuary in a random assignment would be $\sim 8 \%$

\begin{tabular}{|lc|}
\hline Estuary & \% \\
\hline Clarence River (Cla) & 50.0 \\
Port Stephens (PS) & 14.3 \\
Hunter River (HR) & 32.0 \\
Hawkesbury River (HB) & 31.0 \\
Sydney Harbour (SH) & 4.4 \\
Georges River (GR) & 36.7 \\
Port Hacking (PH) & 20.0 \\
Shoalhaven River (SR) & 4.8 \\
Jervis Bay (JB) & 68.4 \\
Clyde River (Cly) & 38.1 \\
Moruya River (MR) & 21.1 \\
Wagonga Inlet (WI) & 52.1 \\
\hline
\end{tabular}



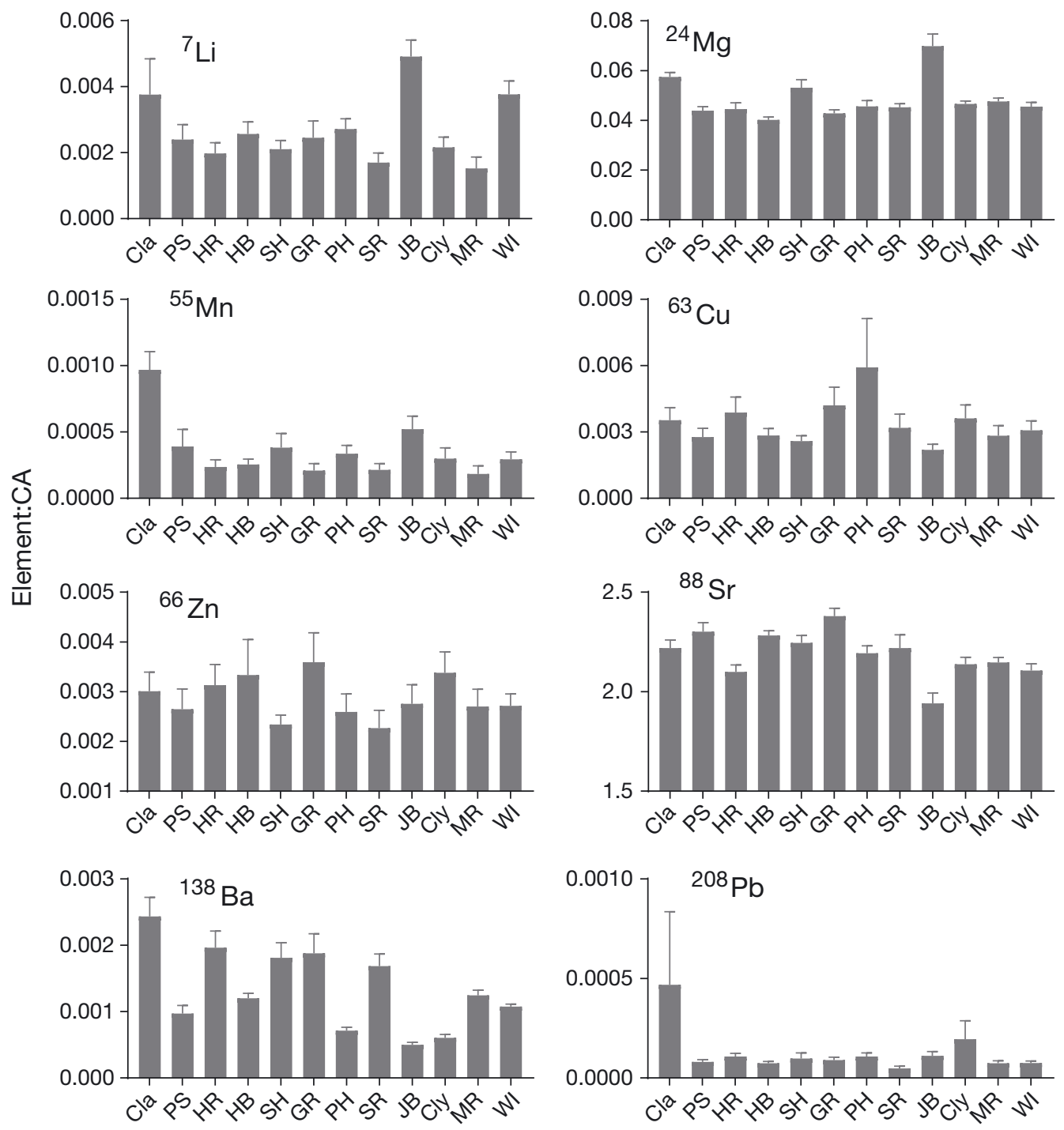

\section{Estuary}

Fig. 2. Element:Ca ratios (mean $\pm 1 \mathrm{SE}$ ) from a spot analysis at the edge of otoliths from juvenile (age-0) Pomatomus saltatrix collected in different estuaries. All units are in $\mathrm{mmol} \mathrm{mol}^{-1}$. Estuaries are arranged by latitude; abbreviations are given in Table 2. These otolith elemental ratios may represent contributions from a variety of sources, including the water, diet and other physiological influences

accuracies from the 3-group analysis allowed the results to be interpreted in a more biologically meaningful way.

\section{Juvenile life period chemical signatures from adult otoliths}

Using the CAP analysis, the chemical composition of the juvenile area of each adult's otolith was used to classify fish to the 3 major estuary groups (Jervis Bay, Clarence River and 'Other estuaries'). A random classification of fish would result in $\sim 33 \%$ assigned to each group. Assuming that most estuaries available for P. saltatrix would have signatures similar to those of the Clarence River (high freshwater) or 'Other estuaries' groups, classification of fish from estuarine nursery areas would likely result in more fish assigned to these 2 groups. However, the majority of the adult fish were classified as having juvenile otolith elemental 'signatures' most similar to those of the Jervis Bay group, and thus most resembling the marine environment $(51.6 \%$ Jervis Bay, 30.3\% Clarence River and $18.0 \%$ 'Other estuaries'). This suggests that both coastal and estuarine environments are important juvenile habitats. 


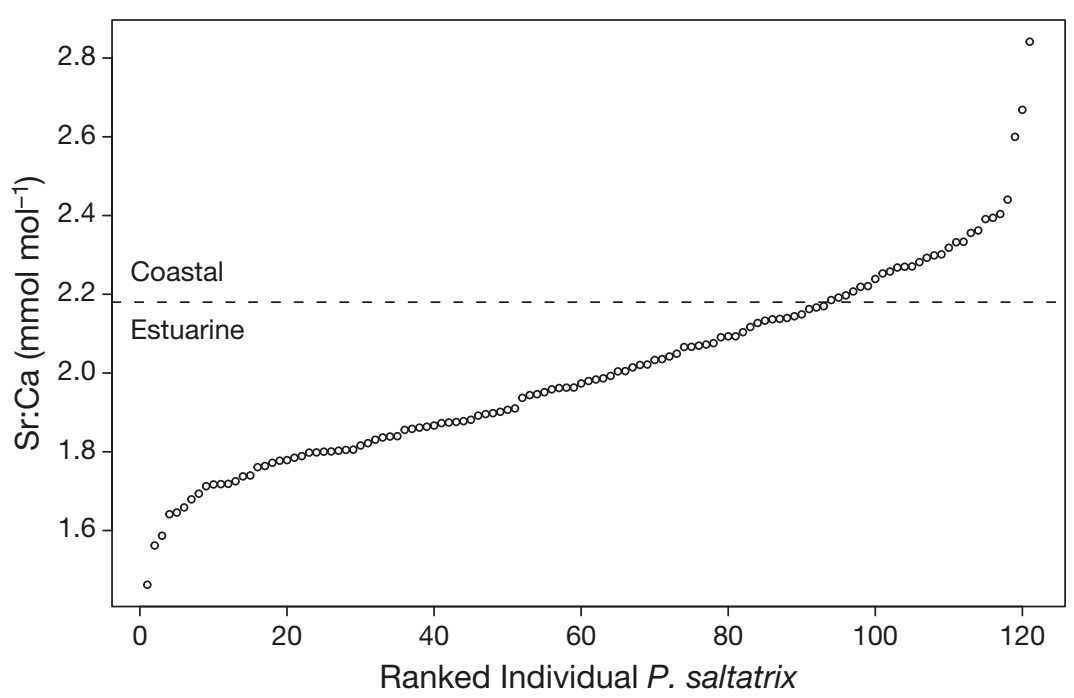

Fig. 3. A visual representation of the continuum of $\mathrm{Sr}: \mathrm{Ca}\left(\mathrm{mmol} \mathrm{mol}^{-1}\right)$ values observed in the spot analyses of the juvenile section from adult otoliths. The numbers on the $x$-axis indicate ranked individual Pomatomus saltatrix. The dashed line shows the calculated threshold between estuarine and coastal waters $\left(2.18 \mathrm{mmol} \mathrm{mol}^{-1}\right)$

The spot analysis of juvenile regions within the adult otoliths revealed a range of $\mathrm{Sr}$ :Ca values (1.462.84; Fig. 3). These spots provide a snapshot of the juvenile phase of many fish and also suggest that juvenile $P$. saltatrix utilise a wide range of salinity environments. A total of $24 \%$ of the spots from the juvenile section of the adult otoliths were above the 2.18 $\mathrm{mmol} \mathrm{mol}{ }^{-1}$ ratio marine water threshold for Sr:Ca. This was less than the percentage of spots considered to have a signature most similar to the marine environment from the multivariate analysis $(52 \%)$, but it corroborates evidence that a substantial proportion of the fish sampled were influenced by the marine environment during their juvenile period.

\section{Otolith elemental profiles}

All elemental profiles of adult $P$. saltatrix showed elevated levels of manganese at the start (Fig. S1 in the Supplement), indicating that the profile started at the core of the otolith (Brophy et al. 2004). Distinct shifts in elemental concentration were observed in the profiles of some otoliths. Sr and Ba profiles showed variation between individual fish, but 4 main patterns were evident (Fig. 4). While over half of the profiles showed a pat-

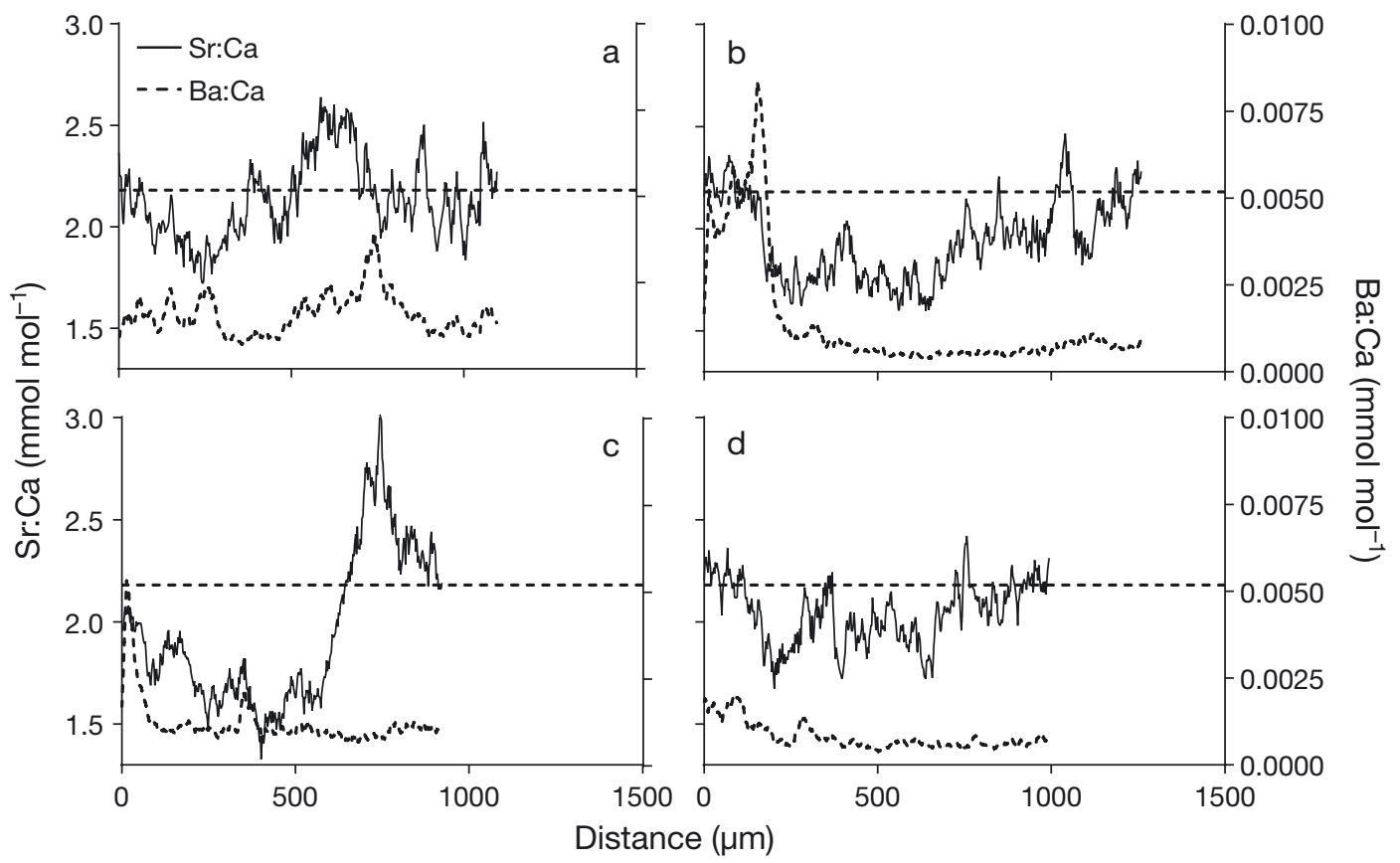

Fig. 4. Examples of profiles of Sr:Ca and Ba:Ca from 1-yr-old Pomatomus saltatrix from the core to the edge of otoliths, showing different life history patterns. Profiles were created using a 7-point moving average. The dashed horizontal line represents the calculated reference criteria for $\mathrm{Sr}: \mathrm{Ca}$ in coastal environments based upon the end points of the profiles from adults caught in coastal environments $\left(2.18 \mathrm{mmol} \mathrm{mol}^{-1}\right)$. These otolith elemental ratios may represent contributions from a variety of sources, including the water, diet and other physiological influences 


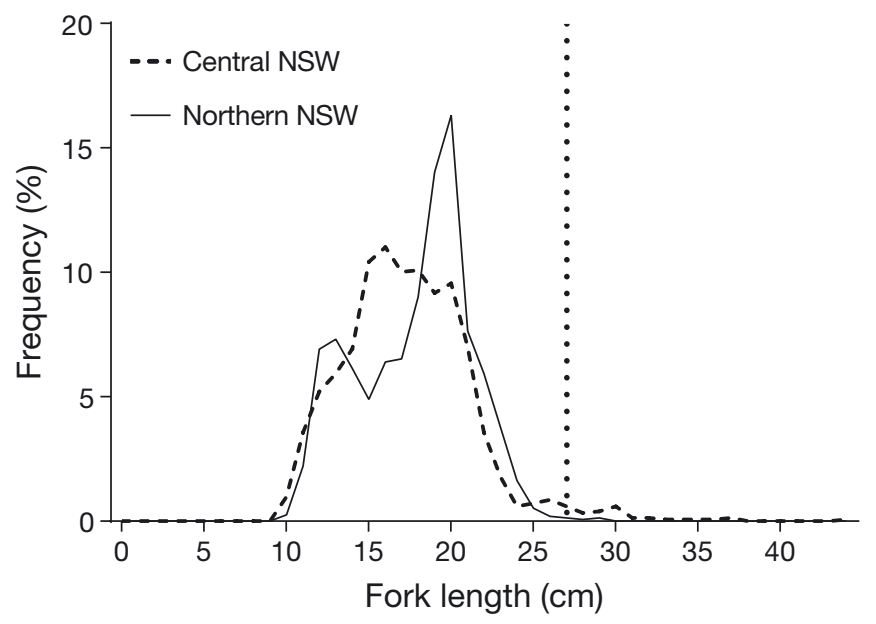

Fig. 5. Compiled length-frequency data of Pomatomus saltatrix in coastal trawls from surveys conducted by the RV 'Kapala' in central NSW (dashed line; $\mathrm{n}=1533$ ) and northern NSW (solid line; $\mathrm{n}=1517$ ) during 1990-1992 and 1995-1996 (Graham et al. 1993a,b, Graham \& Wood 1997). The vertical dotted line represents size at age- 1 , when $P$. saltatrix were previously assumed to emigrate to coastal marine waters (Morton et al. 1993, Zeller et al. 1996)

tern of initially high Ba concentration, which then progressively declined along the profile until approximately $350 \mu \mathrm{m}$ from the otolith core (Fig. 4B,C), other fish did not have this initial spike of $\mathrm{Ba}$ (Fig. 4A,D; Fig. S2 in the Supplement). Sr concentrations initially declined in all fish (until approximately $350 \mu \mathrm{m}$ from the otolith core) before subsequently increasing again once (Fig. 4B) or twice (Fig. 4A; Fig. S2) throughout the life history at approximately 650 and $900-1000 \mu \mathrm{m}$ from the core.

\section{Historical coastal trawl data}

The RV 'Kapala' voyages collected 3050 P. saltatrix. The fish ranged in size from 9 to $37 \mathrm{~cm} \mathrm{FL}$, with the majority being between 11 and $20 \mathrm{~cm}$ FL (Fig. 5), smaller than the age- 1 size of $27 \mathrm{~cm}$ at which fish would emigrate from estuaries (Morton et al. 1993). These juvenile fish were only caught in the nearshore coastal trawls and not the deeper offshore trawls.

\section{DISCUSSION}

Pomatomus saltatrix in eastern Australia show greater life history plasticity than previously hypothesised. Otolith chemistry analysis of both juveniles and adults revealed a more complex and variable life history than expected, which highlights the use of both coastal and estuarine environments during the juvenile phase of $P$. saltatrix in this region. The multiple lines of evidence, including the better than random assignment of fish to estuary of capture, the range of $\mathrm{Sr}: \mathrm{Ca}$ values in the juvenile region of adult otoliths, the evidence of estuary-coast movement in some profiles, and the presence of juvenile tailor in offshore trawls, show that $P$. saltatrix use a mix of estuarine and coastal areas during their juvenile stage, with some individuals potentially only using coastal habitats, as seen in other $P$. saltatrix populations globally (Lenanton et al. 1996, Callihan et al. 2008). This further highlights the importance of both estuaries and coastal regions as habitats for juvenile fish (Able 2005, Nagelkerken et al. 2015, Sheaves et al. 2015).

\section{Juvenile otolith chemistry differences}

The elemental signatures in P. saltatrix otoliths differed significantly among estuaries and among sites within estuaries, indicating that there are interindividual patterns in habitat use at various spatial scales. The lack of consistent differences between all estuaries concurs with previous research in the region (including for the same set of estuaries), which found differences in the otolith chemistry of Pagrus auratus and Pelates sexlineatus from some but not all estuaries (Gillanders 2002a, Sanchez-Jerez et al. 2002). Estuaries are variable environments, influenced by both terrestrial and marine inputs (Roy et al. 2001), and the consequent variation in water chemistry is often reflected in otolith chemistry (Elsdon \& Gillanders 2003, 2004). Water quality and chemistry within an estuary can vary temporally and spatially, and this variability influences the estuarine signatures from the otoliths. Nonetheless, it is not uncommon for otoliths from some estuaries to have similar elemental signatures, particularly in studies with larger numbers of source sites (Gillanders 2002a, Marriott et al. 2016). It is possible that the lack of distinct otolith chemistry signatures between estuaries found in this study is due to $P$. saltatrix visiting multiple source estuaries. While this study suggests movement of juveniles between estuarine and coastal habitats, previous tag-recapture work suggests there is no evidence for movements between estuaries (Morton et al. 1993). Recapture studies are often biased by high sampling effort in close proximity to release locations (Gillanders et al. 2001). However due to the high popularity of $P$. saltatrix with fishers, fishing effort in this region is uniformly high, and no tag was returned from an estuary other than the estu- 
ary in which a fish was tagged. It is thus considered unlikely that the otolith elemental signature of juvenile $P$. saltatrix is being influenced by individuals spending time in multiple estuaries.

It is noted that Jervis Bay, the most marine-dominated estuary, had the lowest average Sr:Ca ratio in the juvenile otoliths. While there was no significant effect of fish length found in the univariate Sr PERMANOVA (Table S3), the fish from Jervis Bay were, on average, the smallest (Table S1) and there were therefore possibly some size-related intrinsic effects on otolith chemistry here such as ontogenetic changes in diet (Buckel et al. 2004, Engstedt et al. 2012) or differing physiology in small P.saltatrix (Grammer et al. 2017). Indeed, decreases in Ba:Ca and Sr:Ca ratios have previously been demonstrated in $P$. saltatrix when switching diet from prawns to fish (Buckel et al. 2004). Fish from Clarence River may have had a higher proportion of crustaceans in their diet (due to their small size) than the fish from some of the other estuaries (Schilling et al. 2017), and this may have been reflected by the high Ba:Ca ratios found for this group. However, this pattern was not seen in similarly small fish collected from Jervis Bay, suggesting, conversely, that diet had a limited impact on Ba:Ca ratios in this group (Izzo et al. 2018). Nevertheless, these patterns could simply reflect the higher freshwater input in Clarence River compared with in Jervis Bay.

Due to the large variation in the otolith chemistry of individual $P$. saltatrix within all the estuaries sampled, it was not possible to link $P$. saltatrix individuals to a particular source estuary, and we rejected our initial hypothesis that $P$. saltatrix otoliths have estuary-specific elemental signatures.

Within-estuary variation has previously been observed in multiple estuaries (Dorval et al. 2005), including some of the same estuaries sampled in this study (Gillanders 2002b, Sanchez-Jerez et al. 2002). There are 2 possible explanations for the within-estuary (site) differences observed in the present study. First, perhaps the highly mobile nature of $P$. saltatrix may result in groups of individuals spending enough time in different areas within an estuary to pick up different chemical signatures. Alternatively, it is possible that there are multiple distinct $P$. saltatrix schools within an estuary which do not mix with one another and thus pick up different chemical signatures. Although juvenile $P$. saltatrix are pelagic predators (Schilling et al. 2017), and are known to roam widely around estuaries (Morton et al. 1993), differences in chemical composition resulting from pollutants have been observed in P. saltatrix at various sites within a single estuary (Sydney Harbour; Man- ning et al. 2017). These spatial differences support the idea that juvenile $P$. saltatrix are resident enough that the bioaccumulation of chemicals is different between areas within a single estuary and thus intraestuary differences in otolith chemistry could be observed in some circumstances.

\section{Assigning adults to estuaries}

The ability to assign individual fish back to specific juvenile sites requires a site-specific baseline of elemental fingerprints. To subsequently discern the contribution of individual nursery habitats to adult populations would require a library of otolith chemistry signatures of all potential source sites (Elsdon et al. 2008). While this study did not have such a library, we were able to test the ability to discriminate $P$. saltatrix source sites using our sampled sites. Although the ability to discriminate individual estuaries based upon juvenile $P$. saltatrix otolith elemental signatures was generally poor, it was still possible to distinguish between 3 main groups: Jervis Bay (the most 'marine' estuary), Clarence River (the estuary with the largest freshwater input) and 'Other estuaries' (other estuaries influenced by variable freshwater flows and marine influences). The allocation of signatures from the juvenile section of adult otoliths back to these groups showed that more than half of these fish had juvenile life stage signatures most similar to the Jervis Bay group $(51.6 \%)$. This indicates that a large proportion of adult $P$. saltatrix have multi-elemental signatures in the juvenile section of their otoliths that are most similar to those found in juveniles from a marine-dominated estuary. The 3 fish that were unable to be allocated to any of our 3 groups may indicate that there was a missing juvenile habitat not sampled; if so, it is likely to be another coastal marine group (possibly a northern group) as our estuary groups encompassed many types of estuaries. We believe it is unlikely that there is another marine group, as a previous study showed that the eastern Australian population is a well-mixed stock along the coast (Nurthen et al. 1992). It is likely that these 3 fish $(<2 \%$ of analysed fish) were outliers in the LA-ICP-MS analysis. The univariate analysis of $\mathrm{Sr}$ :Ca ratios from the spots in the juvenile section of adult otoliths suggested that $24 \%$ of the sampled fish had a significant marine influence in their juvenile life history stage. Combined, the univariate (Sr) and multi-element analysis of the spots suggest that a large proportion (24-52\%) of fish were subject to high marine influence at the time that portion of the otolith was being laid down. 
The sizes of $P$. saltatrix collected by the RV 'Kapala' from coastal marine waters confirm that juvenile (age- $0,<27 \mathrm{~cm})$ P. saltatrix inhabit coastal marine environments, providing the first documented evidence of juveniles in coastal environments. The presence of juveniles in the coastal marine environment is also consistent with the strong marine-influenced signature in $P$. saltatrix otoliths demonstrated by the spot analyses in their juvenile section. This re-affirms the suggestion that a large portion of juvenile $P$. saltatrix spend sufficient time in marine-dominated waters to possess a marine-influenced signature, either in coastal waters or near the entrances to estuaries where coastal water is present. This is particularly clear in the wide range of $\mathrm{Sr}$ : Ca ratios observed in the juvenile section of adult otoliths. These findings conform with the life history patterns observed in other populations of $P$. saltatrix worldwide that indicate the use of both estuarine and coastal nursery habitats (Lenanton et al. 1996, Able et al. 2003, Callihan et al. 2008), and are further supported by our elemental profile analyses.

\section{Elemental profiles}

Our exploratory analysis to determine the suitability of elemental profiles on $P$. saltatrix otoliths revealed multiple patterns in 1-yr-old fish. Assuming the general relationship of increasing $\mathrm{Sr}$ and decreasing Ba with salinity (Campana 1999, Elsdon et al. 2008), some of the observed patterns correspond to the previously documented life history of $P$. saltatrix in eastern Australia: that they spawn in marine environments (high $\mathrm{Sr}$ and low $\mathrm{Ba}$ ) before recruiting to estuaries (lower Sr and higher Ba) and then, after a period of time, return to the marine environment (rising Sr and lower Ba; Bade 1977, Morton et al. 1993, Zeller et al. 1996). Only $58 \%$ of the fish showed Ba rising to a high level initially, while the remaining $42 \%$ only showed a small or negligible rise, suggesting some fish may never enter the less saline regions of estuaries. While the Ba peaks only encompassed a short time period, indicating that lower-salinity estuarine use is limited, the higher Ba concentrations are similar to those recorded in previous research on estuarine fish (Milton et al. 2008, Macdonald \& Crook 2010). The Sr profiles show numerous spikes during the juvenile phase, which suggests movement between estuarine/brackish waters and the coastal marine environments. Overall, results indicate that while some juvenile $P$. saltatrix recruit to estuarine or more freshwater environments, others do not, and they may stay in waters of approximately marine salinity or move between estuaries and the coastal marine environment. This is consistent with the results from the spot analyses and historical trawl samples discussed above, which showed that juveniles are not restricted to estuarine environments. All fish except one (fish 3; Fig. S2) were caught in coastal environments, and as such, the end point of the profiles should represent a marine environment.

Low Ba concentrations at the end of the profile, reflecting the marine environment when the fish was caught, would be expected, and this pattern was observed. Conversely, high Sr concentrations would be expected at the end point of the profiles, and was observed, although there were exceptions. As there is a lag between otolith chemistry and fish movement as new otolith material forms, these 2 exceptions may be due to recent movement between estuarine and coastal environments (Elsdon et al. 2008). The lag in incorporating elements such as Sr into the otolith can be over 20 d in some species (Elsdon \& Gillanders 2005b, Engstedt et al. 2012), which makes it possible that short temporal scales or recent movements between different environments are missed or not fully represented in the elemental profiles.

It is increasingly being shown that otolith chemistry is influenced by numerous intrinsic (e.g. growth and diet) and extrinsic (e.g. temperature, salinity) factors in addition to a simple relationship with water chemistry (Sturrock et al. 2014, 2015, Grammer et al. 2017). A recent meta-analysis highlighted this by demonstrating that whilst salinity was the primary driver of both $\mathrm{Ba}$ and $\mathrm{Sr}, \mathrm{Sr}$ was also influenced by factors including the ecological niche, condition, diet and ontogeny of individual species (Izzo et al. 2018). As such, it is important to note that factors such as diet may be influencing the Sr:Ca profiles presented here (Engstedt et al. 2012). While experimental validation of the variation in otolith Sr and Ba concentrations is important in order to determine the resolution at which movement between the coast and estuaries (or even within estuaries) can be effectively determined, it is possible to use wild-caught fish from known environments to define reference chemical composition thresholds, assuming the otolith edge is representative of capture location. Sr:Ca ratios of $P$. saltatrix from both estuarine and coastal environments have previously been used to generate reference criteria representative of estuarine (3-12 salinity; $\left.1.68 \mathrm{mmol} \mathrm{mol}^{-1}\right)$ and coastal environments ( 35 salinity; $2.2 \mathrm{mmol} \mathrm{mol}^{-1}$ ) around Chesapeake Bay, USA (Takata 2004). The coastal reference value from that study was similar to that in ours, and suggests that a 
Sr:Ca ratio of $\sim 2.2 \mathrm{mmol} \mathrm{mol}^{-1}$ is an appropriate reference level for coastal environments. Sr:Ca ratios lower than $1.68 \mathrm{mmol} \mathrm{mol}^{-1}$ were rarely observed in our study, probably because the salinity in the estuaries sampled in the present study (NSW Office of Environment and Heritage 2012) is rarely as low as that observed in Chesapeake Bay (Takata 2004). The lack of difference in Ba concentrations between the coastal- and estuarine-caught fish in the present study is possibly because the estuarine regions where $P$. saltatrix were collected were higher in salinity $(>25)$ than regions where salinity is low enough to produce the high Ba:Ca signal commonly observed in other studies (Macdonald \& Crook 2010). Overall, analysis of otolith $\mathrm{Sr}: \mathrm{Ca}$ and $\mathrm{Ba}$ :Ca profiles can be used to trace estuarine-ocean movement in $P$. saltatrix, and concur with both the spot analyses and re-analysis of historical coastal length frequencies to indicate that the life history of $P$. saltatrix in eastern Australia is more facultative than previously thought, a finding shared with several studies that have investigated life history patterns in fish (Milton et al. 2008, Gillanders et al. 2015, Condini et al. 2016).

\section{Conclusions}

Analysis of the otolith chemistry of Pomatomus saltatrix from eastern Australia revealed a more plastic life history than previously hypothesised. Due to the weight of evidence from the otolith chemistry analysis, we rejected our initial hypothesis that the juvenile life history region of adult otoliths would have characteristic estuarine signatures. The present study has shown that $P$. saltatrix in eastern Australia use both estuarine and coastal habitats as part of their juvenile development. Furthermore, the use of coastal habitats by juvenile $P$. saltatrix was supported by both otolith elemental profiles and historical length frequencies. These findings further corroborate the applicability of otolith chemistry to evaluate life history patterns and confirm previously undocumented complexity within fish species life histories.

Acknowledgements. We thank Ashley Fowler (NSW DPI) for providing many helpful ideas during the data analysis process, and Aoife Mcfadden for providing assistance with the LA-ICP-MS. Many volunteers, including Chris Stanley, Chris Setio, Matthew Hyatt, Alexandra Milne-Muller, Koren Fang, Gareth Deacon, Chris Lawson, Aaron Puckeridge, Georgia Brook, Dylan van der Meulen and Matthew Broadhurst, helped to collect the juvenile tailor. Many thanks to the fishers who donated fish as part of the NSW Research Angler Program, in particular Ben van der Woude and Aus- tralian Surfcaster. We also thank the Fay family for looking after H.T.S. in Adelaide. This research was supported by an Australian Research Council Linkage Grant (LP150100923), the NSW Recreational Fishing Trust, an Ecological Society of Australia student research award and Hornsby Council. H.T.S. was supported by a Research Training Scholarship. P.R.S. was funded with a Fundação para a Ciência e Tecnologia (FCT) postdoctoral grant (SFRH/BPD/95784/2013). Fish were collected under NSW DPI Scientific Collection Permit no. P03/0086(F)-8.1 and the research was conducted with approval from the NSW DPI Animal Care and Ethics Committee (approval no. SIMS 14/14). This is contribution no. 219 of the Sydney Institute of Marine Science. Thanks also to the 3 anonymous reviewers, who provided many helpful comments.

\section{LITERATURE CITED}

Able KW (2005) A re-examination of fish estuarine dependence: evidence for connectivity between estuarine and ocean habitats. Estuar Coast Shelf Sci 64:5-17

Able KW, Rowe P, Burlas M, Byrne D (2003) Use of ocean and estuarine habitats by young-of-year bluefish (Pomatomus saltatrix) in the New York Bight. Fish Bull 101: 201-214

Anderson M, Gorley RN, Clarke RK (2008) Permanova+ for Primer: guide to software and statistical methods. PrimerE, Plymouth

Bade TM (1977) The biology of tailor (Pomatomus saltatrix Linn.) from the east coast of Australia. MSc thesis, University of Queensland, Brisbane

* Beck MW, Heck KL Jr, Able KW, Childers DL and others (2001) The identification, conservation, and management of estuarine and marine nurseries for fish and invertebrates: a better understanding of the habitats that serve as nurseries for marine species and the factors that create site-specific variability in nursery quality will improve conservation and management of these areas. Bioscience 51:633-641

* Beer NA, Wing SR, Swearer SE (2011) Otolith elemental evidence for spatial structuring in a temperate reef fish population. Mar Ecol Prog Ser 442:217-227

Brophy D, Jeffries TE, Danilowicz BS (2004) Elevated manganese concentrations at the cores of clupeid otoliths: possible environmental, physiological, or structural origins. Mar Biol 144:779-786

Brown JA (2006) Using the chemical composition of otoliths to evaluate the nursery role of estuaries for English sole Pleuronectes vetulus populations. Mar Ecol Prog Ser 306: 269-281

Buckel JA, Sharack BL, Zdanowicz VS (2004) Effect of diet on otolith composition in Pomatomus saltatrix, an estuarine piscivore. J Fish Biol 64:1469-1484

* Callihan JL, Takata LT, Woodland RJ, Secor DH (2008) Cohort splitting in bluefish, Pomatomus saltatrix, in the US mid-Atlantic Bight. Fish Oceanogr 17:191-205

Campana SE (1999) Chemistry and composition of fish otoliths: pathways, mechanisms and applications. Mar Ecol Prog Ser 188:263-297

Campana SE, Thorrold SR (2001) Otoliths, increments, and elements: keys to a comprehensive understanding of fish populations? Can J Fish Aquat Sci 58:30-38

Campana SE, Chouinard GA, Hanson JM, Fréchet A, Brattey J (2000) Otolith elemental fingerprints as biolog- 
ical tracers of fish stocks. Fish Res 46:343-357

Ceyhan T, Akyol O, Ayaz A, Juanes F (2007) Age, growth, and reproductive season of bluefish (Pomatomus saltatrix) in the Marmara region, Turkey. ICES J Mar Sci 64: 531-536

Clarke KR, Tweedley JR, Valesini FJ (2014) Simple shade plots aid better long-term choices of data pre-treatment in multivariate assemblage studies. J Mar Biol Assoc UK 94:1-16

Condini MV, Tanner SE, Reis-Santos P, Albuquerque CQ and others (2016) Prolonged estuarine habitat use by dusky grouper Epinephelus marginatus at subtropical latitudes revealed by otolith microchemistry. Endang Species Res 29:271-277

CSIRO (Commonwealth Scientific and Industrial Research Organisation) (1994) Jervis Bay Baseline Studies, Final Report. Book 2. CSIRO Division of Fisheries

Dodt N, O'Sullivan S, McGilvray J, Jebreen E, Smallwood D, Breddin I (2006) Fisheries long term monitoring program-summary of tailor (Pomatomus saltatrix) survey results: 1999-2004. Department of Primary Industries, Brisbane, Australia

Dorval E, Jones CM, Hannigan R, van Montfrans J (2005) Can otolith chemistry be used for identifying essential seagrass habitats for juvenile spotted seatrout, Cynoscion nebulosus, in Chesapeake Bay? Mar Freshw Res 56:645-653

*Elsdon TS, Gillanders BM (2003) Relationship between water and otolith elemental concentrations in juvenile black bream Acanthopagrus butcheri. Mar Ecol Prog Ser 260:263-272

*Elsdon TS, Gillanders BM (2004) Fish otolith chemistry influenced by exposure to multiple environmental variables. J Exp Mar Biol Ecol 313:269-284

Elsdon TS, Gillanders BM (2005a) Alternative life-history patterns of estuarine fish: barium in otoliths elucidates freshwater residency. Can J Fish Aquat Sci 62:1143-1152

Elsdon TS, Gillanders BM (2005b) Strontium incorporation into calcified structures: separating the effects of ambient water concentration and exposure time. Mar Ecol Prog Ser 285:233-243

Elsdon TS, Wells BK, Campana SE, Gillanders BM and others (2008) Otolith chemistry to describe movements and life-history parameters of fishes: hypotheses, assumptions, limitations and inferences. Oceanogr Mar Biol Annu Rev 46:297-330

Engstedt O, Koch-Schmidt P, Larsson P (2012) Strontium (Sr) uptake from water and food in otoliths of juvenile pike (Esox lucius L.). J Exp Mar Biol Ecol 418-419:69-74

Fodrie FJ, Herzka SZ (2008) Tracking juvenile fish movement and nursery contribution within arid coastal embayments via otolith microchemistry. Mar Ecol Prog Ser 361:253-265

Fowler AM, Smith SM, Booth DJ, Stewart J (2016) Partial migration of grey mullet (Mugil cephalus) on Australia's east coast revealed by otolith chemistry. Mar Environ Res 119:238-244

Geffen AJ, Nash RDM, Dickey-Collas M (2011) Characterization of herring populations west of the British Isles: an investigation of mixing based on otolith microchemistry. ICES J Mar Sci 68:1447-1458

Gillanders BM (2002a) Connectivity between juvenile and adult fish populations: do adults remain near their recruitment estuaries? Mar Ecol Prog Ser 240:215-223

Gillanders BM (2002b) Temporal and spatial variability in elemental composition of otoliths: implications for determining stock identity and connectivity of populations. Can J Fish Aquat Sci 59:669-679

* Gillanders BM, Kingsford MJ (1996) Elements in otoliths may elucidate the contribution of estuarine recruitment to sustaining coastal reef populations of a temperate reef fish. Mar Ecol Prog Ser 141:13-20

*Gillanders BM, Ferrell DJ, Andrew NL (2001) Estimates of movement and life-history parameters of yellowtail kingfish (Seriola lalandi): how useful are data from a cooperative tagging programme? Mar Freshw Res 52:179-192

* Gillanders BM, Able KW, Brown JA, Eggleston DB, Sheridan PF (2003) Evidence of connectivity between juvenile and adult habitats for mobile marine fauna: an important component of nurseries. Mar Ecol Prog Ser 247:281-295

*Gillanders BM, Izzo C, Doubleday ZA, Ye Q (2015) Partial migration: growth varies between resident and migratory fish. Biol Lett 11: 20140850

Graham KJ, Wood BR (1997) Kapala Cruise Report No. 116: the 1995-96 survey of Newcastle and Clarence River prawn grounds. Fisheries Research Institute, Cronulla, NSW

Graham KJ, Liggins GW, Wildforster J, Kennelly SJ (1993a) Kapala Cruise Report No. 110: report for cruises 90-08 to 91-05 conducted between May 1990 and April 1991. Fisheries Research Institute, Cronulla, NSW

Graham KJ, Liggins GW, Wildforster J, Kennelly SJ (1993b) Kapala Cruise Report No. 112: relative abundances and size compositions of prawns and by-catch species on New South Wales prawn grounds during surveys V-VIII (May 1991-May 1992). Fisheries Research Institute, Cronulla, NSW

*Gammer GL, Morrongiello JR, Izzo C, Hawthorne PJ, Middleton JF, Gillanders BM (2017) Coupling biogeochemical tracers with fish growth reveals physiological and environmental controls on otolith chemistry. Ecol Monogr 87:487-507

Griffin W, Powell W, Pearson N, O'Reilly S (2008) GLITTER: data reduction software for laser ablation ICP-MS. Laser Ablation-ICP-MS in the Earth Sciences. Mineralogical Association of Canada Short Course Series 40:204-207

*Helsel DR (2006) Fabricating data: How substituting values for nondetects can ruin results, and what can be done about it. Chemosphere 65:2434-2439

*Hughes JM, Stewart J, Gillanders BM, Collins D, Suthers IM (2016) Relationship between otolith chemistry and age in a widespread pelagic teleost Arripis trutta: influence of adult movements on stock structure and implications for management. Mar Freshw Res 67:224-237

Izzo C, Doubleday ZA, Grammer GL, Gilmore KL and others (2016) Fish as proxies of ecological and environmental change. Rev Fish Biol Fish 26:265-286

*Izzo C, Reis-Santos P, Gillanders BM (2018) Otolith chemistry does not just reflect environmental conditions: a metaanalytic evaluation. Fish Fish, https://doi.org/10.1111/ faf.12264

* Juanes F, Hare JA, Miskiewicz AG (1996) Comparing early life history strategies of Pomatomus saltatrix: a global approach. Mar Freshw Res 47:365-379

* Lazartigues AV, Plourde S, Dodson JJ, Morissette O, Ouellet P, Sirois P (2016) Determining natal sources of capelin in a boreal marine park using otolith microchemistry. ICES J Mar Sci 73:2644-2652

*Lenanton R, Ayvazian S, Pearce A, Steckis R, Young G (1996) Tailor (Pomatomus saltatrix) off Western Australia: 
where does it spawn and how are the larvae distributed? Mar Freshw Res 47:337-346

Macdonald JI, Crook DA (2010) Variability in Sr:Ca and Ba: Ca ratios in water and fish otoliths across an estuarine salinity gradient. Mar Ecol Prog Ser 413:147-161

Manning TM, Roach AC, Edge KJ, Ferrell DJ (2017) Levels of PCDD/Fs and dioxin-like PCBs in seafood from Sydney Harbour, Australia. Environ Pollut 224:590-596

Marriott AL, McCarthy ID, Ramsay AL, Chenery SRN (2016) Discriminating nursery grounds of juvenile plaice (Pleuronectes platessa) in the south-eastern Irish Sea using otolith microchemistry. Mar Ecol Prog Ser 546:183-195

Milton D, Halliday I, Sellin M, Marsh R, Staunton-Smith J, Woodhead J (2008) The effect of habitat and environmental history on otolith chemistry of barramundi Lates calcarifer in estuarine populations of a regulated tropical river. Estuar Coast Shelf Sci 78:301-315

Miskiewicz AG, Bruce BD, Dixon P (1996) Distribution of tailor (Pomatomus saltatrix) larvae along the coast of New South Wales, Australia. Mar Freshw Res 47:331-336

Morton RM, Halliday I, Cameron D (1993) Movement of tagged juvenile tailor (Pomatomus Saltatrix) in Moreton bay, Queensland. Aust J Mar Freshwater Res 44:811-816

Munch SB, Clarke LM (2008) A bayesian approach to identifying mixtures from otolith chemistry data. Can J Fish Aquat Sci 65:2742-2751

* Munro AR, Gillanders BM, Elsdon TS, Crook DA, Sanger AC (2008) Enriched stable isotope marking of juvenile golden perch (Macquaria ambigua) otoliths. Can J Fish Aquat Sci 65:276-285

Nagelkerken I, Sheaves M, Baker R, Connolly RM (2015) The seascape nursery: a novel spatial approach to identify and manage nurseries for coastal marine fauna. Fish Fish 16:362-371

NSW Office of Environment and Heritage (2012) OEH NSW estuaries salinity data compilation 1992 to 2011. NSW Government Public Works, Manly Hydraulic Laboratory, Manly Vale

Nurthen R, Cameron R, Briscoe D (1992) Population genetics of tailor, Pomatomus saltatrix (Linnaeus) (Pisces: Pomatomidae) in Australia. Mar Freshw Res 43:1481-1486

Reis-Santos P, Tanner SE, Vasconcelos RP, Elsdon TS, Cabral HN, Gillanders BM (2013) Connectivity between estuarine and coastal fish populations: contributions of estuaries are not consistent over time. Mar Ecol Prog Ser 491:177-186

Robillard E, Reiss CS, Jones CM (2009) Age-validation and growth of bluefish (Pomatomus saltatrix) along the East Coast of the United States. Fish Res 95:65-75

Rooker JR, Secor DH, Zdanowicz VS, Itoh T (2001) Discrimination of northern bluefin tuna from nursery areas in the Pacific Ocean using otolith chemistry. Mar Ecol Prog Ser 218:275-282

Roy PS, Williams RJ, Jones AR, Yassini I and others (2001) Structure and Function of South-east Australian Estuar-

Editorial responsibility: Stylianos Somarakis, Heraklion, Greece ies. Estuar Coast Shelf Sci 53:351-384

Sanchez-Jerez P, Gillanders BM, Kingsford MJ (2002) Spatial variability of trace elements in fish otoliths: comparison with dietary items and habitat constituents in seagrass meadows. J Fish Biol 61:801-821

Schaffler JJ, Miller TJ, Jones CM (2014) Spatial and temporal variation in otolith chemistry of juvenile Atlantic menhaden in the Chesapeake Bay. Trans Am Fish Soc 143:1061-1071

Schilling HT, Hughes JM, Smith JA, Everett JD, Stewart J, Suthers IM (2017) Latitudinal and ontogenetic variation in the diet of a pelagic mesopredator (Pomatomus saltatrix), assessed with a classification tree analysis. Mar Biol 164:75

Secor DH, Rooker JR (2000) Is otolith strontium a useful scalar of life cycles in estuarine fishes? Fish Res 46:359-371

* Sheaves M, Baker R, Nagelkerken I, Connolly RM (2015) True value of estuarine and coastal nurseries for fish: incorporating complexity and dynamics. Estuar Coast 38: 401-414

Sturrock AM, Trueman CN, Milton JA, Waring CP, Cooper MJ, Hunter E (2014) Physiological influences can outweigh environmental signals in otolith microchemistry research. Mar Ecol Prog Ser 500:245-264

* Sturrock AM, Hunter E, Milton JA, EIMF, Johnson RC, Waring CP, Trueman CN (2015) Quantifying physiological influences on otolith microchemistry. Methods Ecol Evol 6:806-816

Takata LT (2004) Habitat use and cohort recruitment patterns of juvenile bluefish (Pomatomus saltatrix) in diverse Maryland nursery systems. MSc thesis, University of Maryland

Tanner SE, Reis-Santos P, Cabral HN (2016) Otolith chemistry in stock delineation: a brief overview, current challenges and future prospects. Fish Res 173:206-213

*Tanner SE, Reis-Santos P, Vasconcelos RP, Fonseca VF, França S, Cabral HN, Thorrold SR (2013) Does otolith geochemistry record ambient environmental conditions in a temperate tidal estuary? J Exp Mar Biol Ecol 441: $7-15$

Vasconcelos RP, Reis-Santos P, Costa MJ, Cabral HN (2011) Connectivity between estuaries and marine environment: Integrating metrics to assess estuarine nursery function. Ecol Indic 11:1123-1133

* Walther BD, Limburg KE (2012) The use of otolith chemistry to characterize diadromous migrations. J Fish Biol 81: 796-825

Williams J, Jenkins GP, Hindell JS, Swearer SE (2018) Finescale variability in elemental composition of estuarine water and otoliths: developing environmental markers for determining larval fish dispersal histories within estuaries. Limnol Oceanogr 63:262-277

* Zeller BM, Pollock BR, Williams LE (1996) Aspects of the life history and management of tailor (Pomatomus saltatrix) in Queensland. Mar Freshw Res 47:323-329

Submitted: June 19, 2017; Accepted: January 22, 2018 Proofs received from author(s): March 15, 2018 